\title{
云杉天然群体遗传多样性的等位酶变异
}

\author{
罗建勋 ${ }^{1}$ 顾万春 ${ }^{2 *} \quad$ 陈少瑜 $^{3}$ \\ （1 四川省林业科学研究院林业研究所,成都 610081）（2 中国林业科学研究院林业研究所, 北京 10091） \\ （3云南省林业科学院重点实验室, 昆明 650204)
}

摘 要 采用等位酶淀粉凝胶电泳和聚丙烯酰胺凝胶电泳技术对中国西部亚高山特有树种云杉 ( Picea asperata) 10 个天然群体的 300 个个体的遗传多样性和遗传分化进行研究。对 8 个酶系统 17 个酶位点 (27 个等位基因)的检测 分析结果表明, 10 个位点为单态位点, 云杉具有中等偏低的遗传变异水平。群体水平上的遗传多样性指标分别为: 多态位点的百分率 $P_{\mathrm{P}}=29.41 \% \sim 41.18 \%$, 等位基因平均数 $A_{\mathrm{P}}=1.4 \sim 1.6$, 平均期望杂合度 $H_{\mathrm{ep}}=0.06 \sim 0.131$; 种 级水平的遗传多样性指标分别为: $P_{\mathrm{s}}=41.18 \%, A_{\mathrm{s}}=1.2, H_{\mathrm{es}}=0.138$ 。10 个群体的群体水平的观测杂合度为 0.094 3 , 期望杂合度为 $0.0964 ; 10$ 个群体中, 7 个多态位点的单位点的观测杂合度 $\left(H_{0}\right)$ 的均值为 0.229 (变幅为 $0.1429 \sim$ 0.3429 ), 期望杂合度 $\left(H_{\mathrm{e}}\right)$ 的均值为 0.2341 (变幅为 $0.1608 \sim 0.3173$ ), 云杉天然群体间遗传分化度 $\left(F_{\mathrm{ST}}\right)$ 为 0.311 , 云杉群体间变异占总变异的 $31.1 \%$, 基因流低 $\left(N_{\mathrm{m}}=0.5539\right)$, 说明群体间的基因交流有限。异交率高 $(t=0.957)$, 近交率低 $\left(F_{\text {is }}=0.005\right)$, 这些研究结果表明: 云杉群体间等位基因的频率分化显著, 其它云杉属树种基因的渐渗、群 体微生境差异和不同强度的选择压力可能是造成群体间分化显著的主要原因; $F d h-2-B$ 基因与综合生态梯度值呈 显著的负相关 $\left(r=-0.6611^{*}\right), H_{\mathrm{e}}$ 与经度呈显著负相关 $\left(r=-0.683^{*}\right)$, 云杉群体间的地理和遗传距离相关不显 著。10 个群体均含有绝大部分等位基因, 且群体间分化很大, 应加以重点保护和管理, 作为云杉种质资源原地保存 的基地和该树种进一步遗传改良的重要育种群体。

关键词 云杉 天然群体 遗传多样性 等位酶变异

\section{ALLOZYME VARIATION IN 10 NATURAL POPULATIONS OF PICEA ASPERATA}

\author{
LUO Jian-Xun ${ }^{1}$ GU Wan-Chun ${ }^{2}$ and CHEN Shao-Yu ${ }^{3}$ \\ (1 Research Institute of Forestry, Sichuan Academy of Forestry, Chengdu 610081, China) \\ (2 Research Institute of Forestry, Chinese Academy of Forestry, Beijing 100091, China) \\ (3 Key Laboratory of Yunnan Academy of Forestry, Kunming 650204, China)
}

\begin{abstract}
Picea asperata is an important tree for the production of pulp wood and timber and a prime reforestation species in western China. P. asperata occurs in the alpine and canyon regions of northwestern Sichuan Province and southeastern Gansu Province $\left(100^{\circ}-105^{\circ} \mathrm{E}, 30^{\circ}-35^{\circ} \mathrm{N}\right)$, which are important water self-restraint regions. The genetic diversity of ten populations of $P$. asperata in the western part of China was assessed using allozyme analysis by horizontal sliceable starch gel electrophoresis. Seventeen loci (27 alleles) of 8 enzyme systems demonstrated relatively low levels ( mean $H_{\mathrm{e}}=0.096$ ) of genetic variation within populations with values of $P_{\mathrm{P}}=29.41 \%-41.18 \%, A_{\mathrm{P}}=1.4-1.6$ and $H_{\mathrm{ep}}=0.06-0.131$; at the species level, the genetic diversity of $P$. asperata $\left(P_{\mathrm{s}}=41.18 \%, A_{\mathrm{s}}=1.2, H_{\mathrm{es}}=0.138\right)$ was lower than the mean value of long-lived woody angiosperm species $\left(P_{\mathrm{s}}=59.5 \%, A_{\mathrm{s}}=2.10, H_{\mathrm{es}}=0.183\right)$. Genetic diversity is generally the result of long-term evolution. The low level of genetic variation present in $P$. asperata populations may be due to severe contractions in the area of distribution and population size during the last glacial period. Wrights $F$ statistics analysis indicated that $F_{\text {is }}$, a measure of deviation from random mating within the 10 populations, was 0.005 suggesting deviation from Hardy-Weinberg equilibrium and a slight (homozygosity) excess in some populations. The higher level of differentiation $\left(F_{\mathrm{st}}=0.311\right)$ among populations than those of other long-lived woody plants may have resulted from factors such as habitat fragmentation, introgression from another species, variation in environmental conditions and differing selection pressure. Low level of gene flow $\left(N_{\mathrm{m}}=0.5539\right)$, low level of inbreeding ( mean $\left.F_{\text {is }}=0.005\right)$, and high level of outbreeding $\left(F_{\text {is }}=0.005\right)$ could be caused by environmental deterioration and human disturbance, including over-harvesting. There were significantly negative correlations between $F d h-2-B$ gene and ecological gradient value $\left(r=0.6611^{*}\right)$, as
\end{abstract}


well as between expected heterozygosity $\left(H_{\mathrm{e}}\right)$ and longitude $\left(r=0.683^{*}\right)$. It was worth noting that the 10 populations harbored the majority of alleles and had higher genetic diversity suggesting that these populations in particular should be conserved in situ and form population used for tree improvement.

Key words Picea asperata, Natural populations, Genetic diversity, Allozyme marker

云杉属 (Picea) 全世界约 40 种, 中国能形成建 群种的 15 种, 以四川西部、云南西北部和西藏东部 为最丰富的地区, 川西北亚高山地区云杉属种类多 达 13 种,说明了种类的分化强烈和形态变异复杂。 但该特殊地区云杉属植物的遗传背景和遗传多样性 至今不清楚。

云杉属的云杉 $(P$. asperata $)$ 是川西北云杉属中 垂直分布最低树种, 自然分布区跨长江和黄河两大 水系的源头地区, 又是重要的工业用材林树种, 也是 国内生长最快的云杉属树种。云杉森林遗传和树木 改良研究仅涉及天然群体表型多样性、人工林培育 等方面 (李晓清和罗建勋, 2001; 罗建勋和左林, 2001; 罗建勋和顾万春, 2004a, 2004b; 罗建勋和顾 万春,2005), 采用同一套实验材料, 同步进行云杉表 型、等位酶和 DNA 标记的耦合研究 (罗建勋, 2004; Wang et al.,2005)。该研究可为云杉天然基因资源 科学保护和合理利用提供理论依据, 亦为该区域云 杉属其它种的起源、演化和遗传多样性研究提供参 考资料。

国外 1980 2003 年报道有关云杉属植物遗传 多样性研究论文中, 同工酶研究占 $50 \%$ 以上, 涉及 10 个树种, 其中挪威云杉 ( P. abies) 同工酶研究占 $50 \%$ 以上。国内云杉属树种天然群体遗传多样性的 等位酶变异涉及红皮云杉 ( P. koraiensis) (张含国 等, 2000,2003)、西北的青海云杉 ( P. crassifolia)(孙 雪新等, 1990)。也就是说, 同工酶仍是检测松科遗 传多样性的方法 (Modrzynski \& Prus Glowacki, 1998; Ledig et al., 2000; Rajora et al., 2000)之一。

\section{1 材料和方法}

\section{1 材料样本设计}

在云杉天然分布区内分层抽取 10 个群体进行 调查(图 1), 它们分别是甘肃卓尼群体 (10332' E, $34^{\circ} 20^{\prime} \mathrm{N}$, 海拔 $2800 \mathrm{~m}$, )、四川省西北部的阿坝群体 (101 $27^{\prime} \mathrm{E}, 32^{\circ} 33^{\prime} \mathrm{N}$, 海拔 $3100 \mathrm{~m}$ )、若尔盖巴西群 体 $\left(103^{\circ} 13^{\prime} \mathrm{E}, 33^{\circ} 36^{\prime} \mathrm{N}\right.$, 海拔 $2980 \mathrm{~m}$ )、黑水群体 $\left(103^{\circ} 19^{\prime} \mathrm{E}, 32^{\circ} 25^{\prime} \mathrm{N}\right.$, 海拔 $2900 \mathrm{~m}$ )、九寨沟县的大

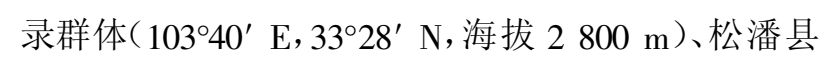
川盘群体 ( $103^{\circ} 37^{\prime} \mathrm{E}, 32^{\circ} 53^{\prime} \mathrm{N}$, 海拔 $3100 \mathrm{~m}$ )、松潘
县林坡群体 $\left(103^{\circ} 38^{\prime} \mathrm{E}, 32^{\circ} 45^{\prime} \mathrm{N}\right.$, 海拔 $3200 \mathrm{~m}$ )、小 金群体 $\left(102^{\circ} 27^{\prime} \mathrm{E}, 31^{\circ} 30^{\prime} \mathrm{N}\right.$, 海拔 $3300 \mathrm{~m}$ )、松潘县 的热务沟群体 $\left(103^{\circ} 27^{\prime} \mathrm{E}, 32^{\circ} 24^{\prime} \mathrm{N}\right.$, 海拔 $2850 \mathrm{~m}$ ) 和 若尔盖县的铁布 (位于甘肃的迭部县境内) 群体 ( $103^{\circ} 08^{\prime} \mathrm{E}, 34^{\circ} 7^{\prime} \mathrm{N}$, 海拔 $2450 \mathrm{~m}$ )。群体和采种母 树选择见文献 (李晓清和罗建勋, 2001; 罗建勋等, 2003)。

依据已有试验评价 (顾万春等, 1998), 在群体内 抽样有效群体 $\left(N_{\mathrm{e}}\right)$ 大小的个体构建试验群体。在 每群体内定距离完成 30 个单株球果采集, 每个单株 采 $40 \sim 60$ 个球果, 球果在温室内分单株脱粒和净 种, 低温 $\left(5{ }^{\circ} \mathrm{C}\right)$ 种质资源库内咜存备用。

\section{2 同工酶电泳}

从每个群体各单株的混合种子中, 随机抽取 8 粒种子, 取其胚乳, 2 粒胚乳混合为一个样, 试验采 用的酶系统和缓冲液系统见表 1, 具体方法见文献 (葛颂, 1988, 1989; 张含国等, 2000; 陈少瑜等, 2001)。

\section{3 酶谱的分析和判读}

酶谱的分析和判读参考文献 (葛颂, 1989; 陈少瑜 等, 2001), 由此获得 8 种酶的基因位点和等位基因。

\section{4 数据处理和遗传分析}

实验数据利用 BIOSYS-11.7 和 POPGENE1.3232 软件处理和运算 ( Swofford \& Selander, 1989; Yang \& Yeh, 1993)。以各基因位点的等位基因频率为基本 数据, 估算基础遗传多样性参数, 详细同工酶遗传多 样性基础参数分析计算见文献 (顾万春, 2004; 葛颂, 1988, 1989), 采用 Mantel's 检验群体间遗传距离和 地理距离的相关性。

\section{2 结果与分析}

\section{1 遗传多样性分析}

\subsection{1 等位基因频率和等位基因分化}

通过对 10 个群体 13 个酶系统 (ACP、AAT、 ADH、EST、GDH、G6PD、IDH、ME、MDH、PGD-6、PGI、 PGM 和 SKD) 的筛选, 选定 8 种分离良好、酶带清晰 的酶系统 (AAT、GDH、FDH、IDH、MDH、PGD、ADH 和 $\mathrm{SKD})$ 。根据不同酶谱带在个体和群体中分布, 参考 裸子植物有关酶系统的文献, 尤其是云杉属植物的 等位酶分析资料, 最终确定了 17 个基因位点, 共发 


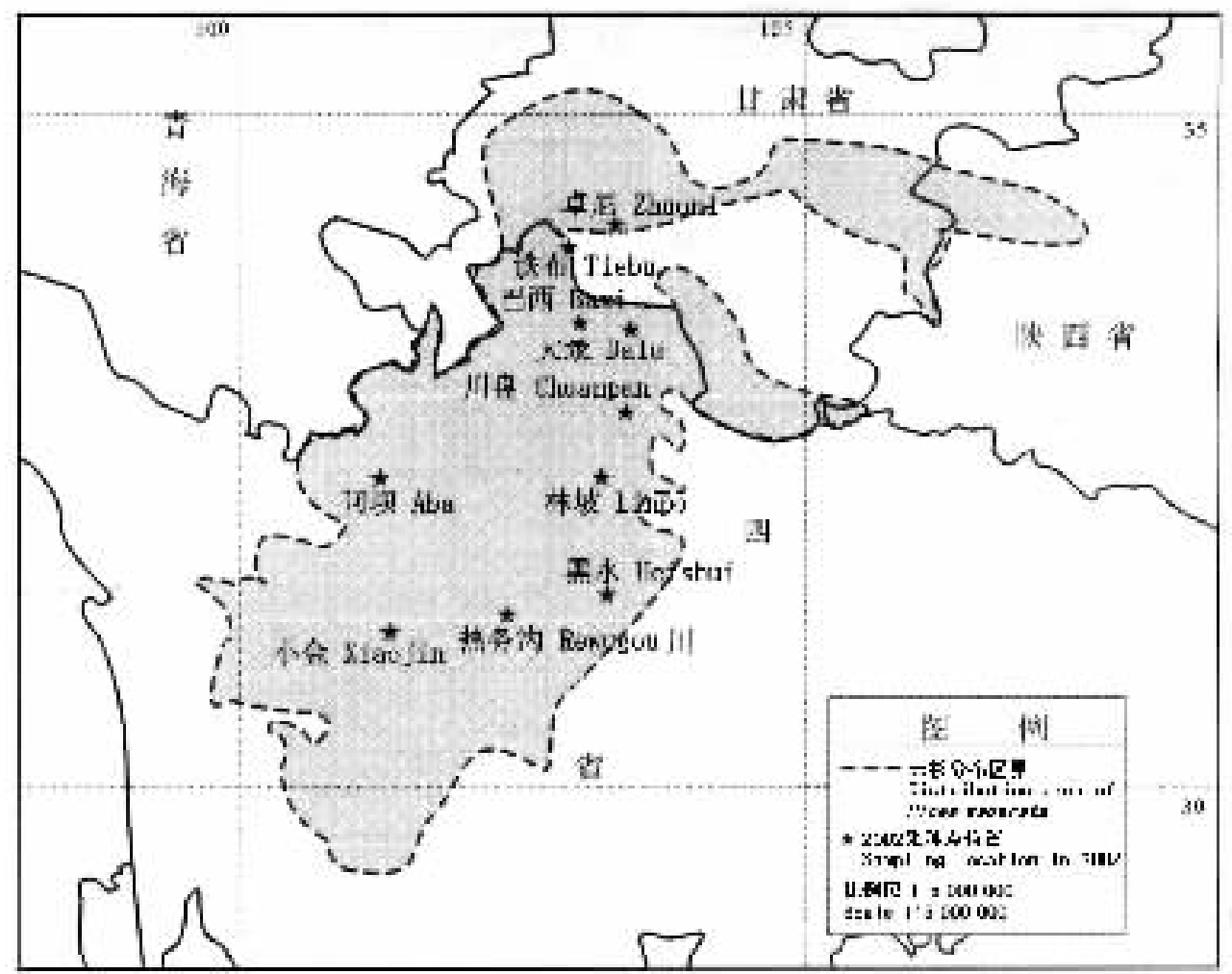

图 1 云杉采种点分布图

Fig. 1 The sampling location of Picea asperata in China

表 18 种酶系统和缓冲液系统以及每个酶系统检测到位点数

Table 18 enzyme systems assayed and relevant buffers, and loci detected in Picea asperata

\begin{tabular}{lccc}
\hline \multicolumn{1}{c}{ 酶系统 Enzyme system } & EC 代号 EC No. & 缓冲液系统 Buffer system & 位点数 No. of loci \\
\hline 天冬氨酸转氨酶 Aspartate aminotransferase (ATT) & E.C.2.6.1.1 & S6 & 4 \\
谷氨酸脱氢酶 Glutamate dehydrogenase (GDH) & E.C.1.4.1.2 & S1 & 1 \\
甲酸脱氢酶 Formate dehydrogenase (FDH) & E.C.1.2.1.2 & W2 & 2 \\
异柠檬酸脱氢酶 Isocitrate dehydrogenase (IDH) & E.C.1.1.1.42 & W2 & 2 \\
苹果酸脱氢酶 Malate dehydrogenase (MDH) & E.C.1.1.1.37 & W2 & 3 \\
磷酸葡萄糖酸脱氢酶 Malate dehydrogenase (PGD) & E.C.1.1.1.44 & S1 & 3 \\
乙醇脱氢酶 Alcohol dehydrogenase (ADH) & E.C.1.1.1.1 & W2 & 1 \\
莽草酸脱氢酶 Shikimate dehydrogenase (SKD) & E.C.1.1.1.25 & & 1 \\
\hline
\end{tabular}

缓冲液系统代号见文献(周世良等, 1998) No. of buffer system see Zhou et al., 1998

现 27 个等位基因,等位基因频率的分布见表 2 。7 个位点为遗传多态位点 (当群体中某位点有两个以 上等位基因而且每个等位基因的频率均在 0.01 以 上时, 该位点就被称为多态位点), 占 $41.18 \%$, 其余 10 个位点为单态位点。 $A a t-2, F d h-2$ 和 $I d h-2$ 含 3 个等位基因,属复等位基因; Idh- $1 、 M d h-1 、 M d h-3$ 和 $P g d-1$ 含 2 个等位基因, 其余位点均为单态位点。从 表 2 中可知, 10 个单态位点基因和 7 个多态位点的 19 个大量基因在 10 个群体均有分布, 根据 Kim 等 (1994)对等位基因的划分, 认为 19 个 $(10+9)$ 基因
属全域基因 (其中 10 个基因的频率为 1.000 , 存在于 10 个群体; 9 个基因的基因频率小于 1.000 , 存在于 9 个群体), 占总基因的 $70.37 \%$; 有 7 个等位基因存 在于 $7 \sim 9$ 个群体, 为广域基因, 占总基因的 $25.93 \%$; 该试验未检测到局域基因; 特有基因只有 一个, 即铁布群体的 $I d h-2-\mathrm{C}$, 占总基因的 $3.7 \%$ 。每 个群体检测到的等位基因及其数目不同, 铁布检测 到的最多,等位基因数为 27 个, 川盘、卓尼、巴西次 之, 等位基因数为 26 个, 最少的群体为小金、黑水和 林坡, 等位基因数为 23 个, 平均每个群体检测到的 
等位基因数均值为 24.7 个。从表 2 还可看出, 10 个 群体基因频率的均值没有太大的差异。特有基因通 常分布范围有限, 地方性特有基因是群体为适应特 定生态环境而产生, 其存在反映了群体遗传组成上 的差异。各群体的全域基因和广域基因的不同, 在 一定程度上反映了各群体间等位基因存在的差异。 而且相同位点的广域基因频率在群体间均有差异。

2.1.2 种级和群体水平的遗传多样性

每个位点的平均等位基因数 $(A)$ 、多态位点的 百分率 $(P)$ 、以及平均观察杂合度 $\left(H_{0}\right)$ 和平均期望 杂合度 $\left(H_{\mathrm{e}}\right)$ 是反映群体遗传多样性的基础指标。
云杉遗传多样性参数指标见表 3 。

对 10 个群体的 300 个个体的检测结果表明, 种 级水平的每个位点的等位基因平均数为 $A$ 为 1.588 , 多态位点百分率 $P$ 占 $41.18 \%$, 观测杂合度 $H_{\mathrm{e}}$ 为 0.1378 。在群体水平, 上述指标略有降低, 10 个群体平均遗传变异水平: $P$ 为 $37.06 \%$ (变幅为 $29.41 \% \sim 41.18 \%$ ),$A$ 为 1.453 (变幅为 $1.353 \sim$ 1.588 )、 $A_{\mathrm{e}}$ 为 1.151 (变幅为 $1.083 \sim 1.220$ ), $H_{\mathrm{e}}$ 为 0.096(变幅为 $0.066 \sim 0.131$ )。云杉遗传多样性在 10 个群体存在一定差异, 其中等位基因数目最高为 铁布群体 ( $A=1.588)$, 其次是卓尼、川盘和巴西 4 个

表 2 云杉群体的等位基因频率分布

Table 2 Distribution of allele frequencies at 17 isozyme gene loci in ten populations of Picea asperata

\begin{tabular}{|c|c|c|c|c|c|c|c|c|c|c|c|c|}
\hline \multirow{3}{*}{$\begin{array}{l}\text { 位点 } \\
\text { Locus }\end{array}$} & \multirow{3}{*}{$\begin{array}{c}\text { 等位基因 } \\
\text { Allele }\end{array}$} & \multicolumn{11}{|c|}{ 群体 Population } \\
\hline & & 小金 & 川盘 & 铁布 & 阿坝 & 黑水 & 卓尼 & 林坡 & 大录 & 巴西 & 热务沟 & 平均 \\
\hline & & & Chuanpan & & & Heishui & Zhuoni & Linpo & & & Rewugou & Mean \\
\hline Aat-1 & A & 1.000 & 1.000 & 1.000 & 1.000 & 1.000 & 1.000 & 1.000 & 1.000 & 1.000 & 1.000 & 1.000 \\
\hline \multirow[t]{3}{*}{ Aat -2} & A & 0.050 & 0.017 & 0.117 & 0.000 & 0.000 & 0.267 & 0.083 & 0.100 & 0.067 & 0.000 & 0.070 \\
\hline & B & 0.950 & 0.967 & 0.833 & 0.933 & 0.917 & 0.667 & 0.917 & 0.817 & 0.917 & 0.883 & 0.875 \\
\hline & $\mathrm{C}$ & 0.000 & 0.017 & 0.050 & 0.067 & 0.083 & 0.066 & 0.000 & 0.083 & 0.017 & 0.117 & 0.050 \\
\hline Aat -3 & A & 1.000 & 1.000 & 1.000 & 1.000 & 1.000 & 1.000 & 1.000 & 1.000 & 1.000 & 1.000 & 1.000 \\
\hline Aat-4 & A & 1.000 & 1.000 & 1.000 & 1.000 & 1.000 & 1.000 & 1.000 & 1.000 & 1.000 & 1.000 & 1.000 \\
\hline Adh & A & 1.000 & 1.000 & 1.000 & 1.000 & 1.000 & 1.000 & 1.000 & 1.000 & 1.000 & 1.000 & 1.000 \\
\hline$F d h-1$ & A & 1.000 & 1.000 & 1.000 & 1.000 & 1.000 & 1.000 & 1.000 & 1.000 & 1.000 & 1.000 & 1.000 \\
\hline \multirow[t]{3}{*}{ Fdh-2 } & A & 0.183 & 0.517 & 0.233 & 0.033 & 0.000 & 0.167 & 0.250 & 0.300 & 0.467 & 0.017 & 0.217 \\
\hline & B & 0.700 & 0.417 & 0.717 & 0.600 & 1.000 & 0.733 & 0.683 & 0.700 & 0.450 & 0.917 & 0.692 \\
\hline & $\mathrm{C}$ & 0.117 & 0.067 & 0.050 & 0.367 & 0.000 & 0.100 & 0.067 & 0.000 & 0.083 & 0.067 & 0.092 \\
\hline$G d h$ & A & 1.000 & 1.000 & 1.000 & 1.000 & 1.000 & 1.000 & 1.000 & 1.000 & 1.000 & 1.000 & 1.000 \\
\hline \multirow[t]{2}{*}{ Idh-I } & A & 1.000 & 0.833 & 0.900 & 0.700 & 0.900 & 0.083 & 1.000 & 0.983 & 0.933 & 0.600 & 0.793 \\
\hline & B & 0.000 & 0.167 & 0.100 & 0.300 & 0.100 & 0.917 & 0.000 & 0.017 & 0.067 & 0.400 & 0.207 \\
\hline \multirow[t]{3}{*}{$I d h-2$} & A & 0.000 & 0.150 & 0.067 & 0.017 & 0.083 & 0.833 & 0.000 & 0.033 & 0.050 & 0.000 & 0.123 \\
\hline & B & 1.000 & 0.850 & 0.917 & 0.983 & 0.917 & 0.167 & 1.000 & 0.967 & 0.950 & 1.000 & 0.875 \\
\hline & C & 0.000 & 0.000 & 0.017 & 0.000 & 0.000 & 0.000 & 0.000 & 0.000 & 0.000 & 0.000 & 0.002 \\
\hline \multirow[t]{2}{*}{ Mdh-I } & A & 0.383 & 0.800 & 0.950 & 0.900 & 0.883 & 0.150 & 0.950 & 0.883 & 0.917 & 0.917 & 0.763 \\
\hline & B & 0.617 & 0.200 & 0.050 & 0.100 & 0.117 & 0.850 & 0.050 & 0.012 & 0.083 & 0.083 & 0.227 \\
\hline Mdh-2 & A & 1.000 & 1.000 & 1.000 & 1.000 & 1.000 & 1.000 & 1.000 & 1.000 & 1.000 & 1.000 & 1.000 \\
\hline \multirow[t]{2}{*}{$M d h-3$} & A & 0.250 & 0.133 & 0.217 & 0.000 & 0.200 & 0.833 & 0.283 & 0.183 & 0.017 & 0.250 & 0.230 \\
\hline & B & 0.750 & 0.867 & 0.783 & 1.000 & 0.800 & 0.167 & 0.717 & 0.817 & 0.983 & 0.750 & 0.763 \\
\hline \multirow[t]{2}{*}{ Pgd-I } & A & 0.067 & 0.600 & 0.800 & 0.933 & 0.950 & 0.933 & 0.550 & 0.667 & 0.900 & 0.950 & 0.735 \\
\hline & B & 0.933 & 0.400 & 0.200 & 0.067 & 0.050 & 0.067 & 0.450 & 0.333 & 0.100 & 0.050 & 0.265 \\
\hline$P g d-2$ & A & 1.000 & 1.000 & 1.000 & 1.000 & 1.000 & 1.000 & 1.000 & 1.000 & 1.000 & 1.000 & 1.000 \\
\hline Pgd-3 & A & 1.000 & 1.000 & 1.000 & 1.000 & 1.000 & 1.000 & 1.000 & 1.000 & 1.000 & 1.000 & 1.000 \\
\hline Skd & A & 1.000 & 1.000 & 1.000 & 1.000 & 1.000 & 1.000 & 1.000 & 1.000 & 1.000 & 1.000 & 1.000 \\
\hline \multicolumn{2}{|c|}{$\begin{array}{l}\text { 基因频率平均值 } \\
\text { Mean value of gene frequency }\end{array}$} & 0.630 & 0.630 & 0.630 & 0.630 & 0.630 & 0.630 & 0.630 & 0.630 & 0.630 & 0.630 & 0.630 \\
\hline \multicolumn{2}{|c|}{$\begin{array}{l}\text { 等位基因数 } \\
\text { Number of alleles }\end{array}$} & 23.000 & 26.000 & 27.000 & 24.000 & 23.000 & 26.000 & 23.000 & 25.000 & 26.000 & 24.000 & 24.700 \\
\hline
\end{tabular}


表 3 云杉 10 个群体的 17 个等位基因位点的遗传变异

Table 3 Genetic diversity of 17 allele loci of 10 populations in Picea asperata

\begin{tabular}{|c|c|c|c|c|c|c|c|c|}
\hline $\begin{array}{c}\text { 群体 } \\
\text { Population }\end{array}$ & $\begin{array}{c}\text { 个体 } \\
\text { Individual }\end{array}$ & $\begin{array}{c}\text { 等位基因数 } \\
A\end{array}$ & $\begin{array}{c}\text { 有效等位基因 } \\
\text { 数目 } A_{\mathrm{e}}\end{array}$ & $\begin{array}{l}\text { 多态位点 } \\
\text { 百分率 } P\end{array}$ & $\begin{array}{c}\text { 异交率 } \\
\text { Outbreeding } \\
\text { coefficient }\end{array}$ & $\begin{array}{l}\text { Shanonon } \\
\text { 信息指数 } I\end{array}$ & $\begin{array}{c}\text { 观测杂合度 } \\
H_{0}\end{array}$ & $\begin{array}{c}\text { 期望杂合度 } \\
H_{\mathrm{e}}\end{array}$ \\
\hline 小金 Xiaojin & 30 & $1.3529(0.6063)$ & $1.1533(0.3103)$ & 29.41 & 0.628114 & $0.1460(0.2686)$ & $0.0706(0.1734)$ & $0.0915(0.1734)$ \\
\hline 川盘 Chuanpan & 30 & $1.5294(0.7174)$ & $1.2199(0.3681)$ & 41.18 & 1.000000 & $0.2056(0.2889)$ & $0.1412(0.2009)$ & $0.1306(0.1903)$ \\
\hline 铁布 Tiebu & 30 & $1.5882(0.7952)$ & $1.1560(0.2368)$ & 41.18 & 1.000000 & $0.1856(0.2532)$ & $0.1137(0.1663)$ & $0.1082(0.1523)$ \\
\hline 阿坝 Aba & 30 & $1.4118(0.6183)$ & $1.1341(0.2899)$ & 35.29 & 1.000000 & $0.1352(0.2392)$ & $0.0941(0.1927)$ & $0.0829(0.1572)$ \\
\hline 黑水 Heishui & 30 & $1.3529(0.4926)$ & $1.0833(0.1358)$ & 35.29 & 1.000000 & $0.1152(0.1704)$ & $0.0706(0.1166)$ & $0.0662(0.1020)$ \\
\hline 卓尼 Zhuoni & 30 & $1.5294(0.7174)$ & $1.1747(0.2809)$ & 41.18 & 1.000000 & $0.1956(0.2762)$ & $0.1176(0.1708)$ & $0.1149(0.1624)$ \\
\hline 林坡 Linpo & 30 & $1.3529(0.6063)$ & $1.1660(0.3322)$ & 29.41 & 0.949546 & $0.1504(0.2722)$ & $0.0941(0.1879)$ & $0.0966(0.1809)$ \\
\hline 大录 Dalu & 30 & $1.4706(0.6243)$ & $1.1633(0.2716)$ & 41.18 & 0.536357 & $0.1716(0.2532)$ & $0.0745(0.1288)$ & $0.1067(0.1656)$ \\
\hline 巴西 Baxi & 30 & $1.5294(0.7174)$ & $1.1297(0.3219)$ & 41.18 & 0.598778 & $0.1406(0.2393)$ & $0.0588(0.0939)$ & $0.0785(0.1465)$ \\
\hline 热务沟 Rewugou & 30 & $1.4118(0.6183)$ & $1.1324(0.2572)$ & 35.29 & 1.000000 & $0.1417(0.2218)$ & $0.1078(0.2152)$ & $0.0876(0.1491)$ \\
\hline $\begin{array}{l}\text { 种级水平 } \\
\text { At species level }\end{array}$ & 300 & $1.5882(0.7952)$ & $1.2163(0.2953)$ & 41.18 & I & $0.2244(0.2881)$ & $0.0943(0.1271)$ & $0.1378(0.1785)$ \\
\hline $\begin{array}{l}\text { 群体平均水平 } \\
\text { At population level }\end{array}$ & 30 & 1.4529 & 1.1513 & 37.06 & 0.9574 & 0.1588 & 0.0943 & 0.0964 \\
\hline
\end{tabular}

括号内数字是标准误差 The numbers in parentheses are standard errors $A$ : Number of alleles per locus $A_{\mathrm{e}}$ : Effective number of alleles per locus $P$ : Percentage of polymorphic loci (99\% criterion) I: The shinnon information index $H_{\mathrm{o}}$ : Observed heterozygosity $H_{\mathrm{e}}$ : Expected heterozxgosity

群体 ( $A=1.529)$, 最低为热务沟、黑水和小金群体 $(A=1.353)$; 多态位点百分率最高为卓尼、铁布、川 盘、大录和巴西群体 $(P=41.18 \%)$, 其次是阿坝、热 务沟和黑水群体 $(P=35.29 \%)$, 最低为林坡和小金 群体 $(P=29.41 \%)$ 。平均期望杂合度最高的为川 盘群体 $\left(H_{\mathrm{e}}=0.131\right)$, 最低的是黑水群体 $\left(H_{\mathrm{e}}=\right.$ 0.066)。而且,所有群体的平均期望杂合度与观测 杂合度相差不大。7 个多态位点单位点杂合度群体 间差异明显, 从表 4 看出, 川盘、卓尼和铁布拥有最 高的单位点杂合度, 3 个群体单位点的观测杂合度 的均值分别为 $0.3429 、 0.2857$ 和 0.2762 , 3 个群体
单位点的期望杂合度的均值分别为 $0.3173 、 0.2791$ 和 0.2627 。从对云杉天然群体固定指数 $(F)$ 及其分 化程度的分析可知 (表 5): 在 62 个检验中 (检验各 群体各位点的 $F$ 值), 47 个(占 $75.81 \%$ ) 符合 HardyWeinberg 平衡 $(p \geqslant 0.05), 15$ 个基因位点显著偏离 Hardy-Weinberg 平衡。群体平均固定指数 $(F)$ 为 0.005(从表 7 可以看出, Idh-1、Idh-2 和 $M d h-33$ 个 位点呈现杂合体过量, $F_{\text {is }}$ 的变幅为 $-0.130 \sim$ $-0.2631, P g d-1$ 位点呈现杂合体缺乏, $F_{\text {is }}=$ 0.288 ), 很明显少部分群体 (占 $24.19 \%$ ) 呈现轻微 纯合子过量状态, 但大部分群体基本符合 Hardy-

表 4 云杉 10 个群体的单位点杂合度

Table 4 Observed heterozygosity at single locus detected in ten populations of Picea asperata

\begin{tabular}{|c|c|c|c|c|c|c|c|c|c|c|c|c|}
\hline $\begin{array}{l}\text { 位点 } \\
\text { Locus }\end{array}$ & $\begin{array}{c}\text { 杂合度 } \\
\text { Heterozy gosity }\end{array}$ & $\begin{array}{c}\text { 小金 } \\
\text { Xiaojin }\end{array}$ & $\begin{array}{c}\text { 川盘 } \\
\text { Chuanpan }\end{array}$ & $\begin{array}{l}\text { 铁布 } \\
\text { Tiebu }\end{array}$ & $\begin{array}{c}\text { 阿坝 } \\
\text { Aba } \\
\end{array}$ & $\begin{array}{c}\text { 黑水 } \\
\text { Heishui }\end{array}$ & $\begin{array}{l}\text { 卓尼 } \\
\text { Zhuoni }\end{array}$ & $\begin{array}{l}\text { 林坡 } \\
\text { Linpo }\end{array}$ & $\begin{array}{l}\text { 大录 } \\
\text { Dalu }\end{array}$ & $\begin{array}{l}\text { 巴西 } \\
\text { Baxi }\end{array}$ & $\begin{array}{l}\text { 热务沟 } \\
\text { Rewugou }\end{array}$ & $\begin{array}{c}\text { 平均值 } \\
\text { Mean }\end{array}$ \\
\hline \multirow[t]{2}{*}{ Aat-2 } & $H_{\mathrm{o}}$ & 0.1000 & 0.0667 & 0.2667 & 0.1333 & 0.1000 & 0.5333 & 0.1000 & 0.2333 & 0.1667 & 0.2333 & 0.1933 \\
\hline & $H_{\mathrm{e}}$ & 0.0966 & 0.0661 & 0.2944 & 0.1266 & 0.1554 & 0.4881 & 0.1554 & 0.3215 & 0.1576 & 0.2096 & 0.2071 \\
\hline \multirow[t]{2}{*}{ Fdh-2 } & $H_{\mathrm{o}}$ & 0.5667 & 0.4333 & 0.4333 & 0.5667 & 0.0000 & 0.3667 & 0.5333 & 0.3333 & 0.3333 & 0.1667 & 0.3733 \\
\hline & $H_{\mathrm{e}}$ & 0.4706 & 0.5644 & 0.4367 & 0.5130 & 0.0000 & 0.4316 & 0.4740 & 0.4271 & 0.5825 & 0.1576 & 0.4058 \\
\hline \multirow[t]{2}{*}{$I d h-1$} & $H_{\mathrm{o}}$ & 0.0000 & 0.3333 & 0.1333 & 0.6000 & 0.2000 & 0.1000 & 0.0000 & 0.0333 & 0.1333 & 0.8000 & 0.2333 \\
\hline & $H_{\mathrm{e}}$ & 0.0000 & 0.2825 & 0.1831 & 0.4271 & 0.1831 & 0.1554 & 0.0000 & 0.0333 & 0.1266 & 0.4881 & 0.1879 \\
\hline \multirow[t]{2}{*}{$I d h-2$} & $H_{\mathrm{o}}$ & 0.0000 & 0.3000 & 0.1667 & 0.0333 & 0.1667 & 0.3333 & 0.0000 & 0.0667 & 0.1000 & 0.0000 & 0.1167 \\
\hline & $H_{\mathrm{e}}$ & 0.0000 & 0.2593 & 0.1576 & 0.0333 & 0.1554 & 0.2825 & 0.0000 & 0.0655 & 0.0966 & 0.0000 & 0.1050 \\
\hline \multirow[t]{2}{*}{$M d h-1$} & $H_{\mathrm{o}}$ & 0.2333 & 0.4000 & 0.1000 & 0.2000 & 0.2333 & 0.3000 & 0.1000 & 0.2333 & 0.1667 & 0.1667 & 0.2133 \\
\hline & $H_{\mathrm{e}}$ & 0.4808 & 0.3254 & 0.0966 & 0.1831 & 0.2096 & 0.2593 & 0.0966 & 0.2096 & 0.1554 & 0.1554 & 0.2172 \\
\hline \multirow[t]{2}{*}{$M d h-3$} & $H_{\mathrm{o}}$ & 0.2333 & 0.2667 & 0.4333 & 0.0000 & 0.4000 & 0.2333 & 0.5667 & 0.3667 & 0.0333 & 0.4333 & 0.2967 \\
\hline & $H_{\mathrm{e}}$ & 0.3814 & 0.2350 & 0.3452 & 0.0000 & 0.3254 & 0.2096 & 0.4130 & 0.3045 & 0.0333 & 0.3814 & 0.2629 \\
\hline \multirow[t]{2}{*}{$P g d-1$} & $H_{\mathrm{o}}$ & 0.0667 & 0.6000 & 0.4000 & 0.0667 & 0.1000 & 0.1333 & 0.3000 & 0.0000 & 0.0667 & 0.0333 & 0.1769 \\
\hline & $H_{\mathrm{e}}$ & 0.1266 & 0.4881 & 0.3254 & 0.1266 & 0.0966 & 0.1266 & 0.5034 & 0.4520 & 0.1831 & 0.0966 & 0.2525 \\
\hline 平均值 & $H_{\mathrm{o}}$ & 0.1714 & 0.3429 & 0.2762 & 0.2286 & 0.1714 & 0.2857 & 0.2286 & 0.1809 & 0.1429 & 0.2619 & 0.2290 \\
\hline Mean & $H_{\mathrm{e}}$ & 0.2223 & 0.3173 & 0.2627 & 0.2014 & 0.1608 & 0.2791 & 0.2346 & 0.2591 & 0.1907 & 0.2127 & 0.2341 \\
\hline
\end{tabular}


表 5 每群体多态位点固定指数 $\boldsymbol{F}$ 值及其 $\boldsymbol{\chi}^{2}$ 检验其偏离 $\mathbf{0}$ 值的程度

Table 5 Value of fixation index (inbreeding coefficient) $F$ for polymorphic loci in the 10 populations of Picea asperata and its conformance to Hardy-Weinberg equilibrium, ie. statistical difference of values from zero, which was tested using chi-square analysis

\begin{tabular}{|c|c|c|c|c|c|c|c|c|c|c|}
\hline $\begin{array}{l}\text { 位点 } \\
\text { Locus }\end{array}$ & $\begin{array}{l}\text { 小金 } \\
\text { Xaojin }\end{array}$ & $\begin{array}{c}\text { 川盘 } \\
\text { Chuanpan }\end{array}$ & $\begin{array}{l}\text { 铁布 } \\
\text { Tiebu }\end{array}$ & $\begin{array}{c}\text { 阿坝 } \\
\text { Aba }\end{array}$ & $\begin{array}{l}\text { 黑水 } \\
\text { Heishui }\end{array}$ & $\begin{array}{l}\text { 卓尼 } \\
\text { Zhuoni }\end{array}$ & $\begin{array}{l}\text { 林坡 } \\
\text { Linpo }\end{array}$ & $\begin{array}{l}\text { 大录 } \\
\text { Dalu }\end{array}$ & $\begin{array}{l}\text { 巴西 } \\
\text { Baxi }\end{array}$ & $\begin{array}{l}\text { 热务沟 } \\
\text { Rewugou }\end{array}$ \\
\hline Aat -2 & $-0.0526^{\mathrm{ns}}$ & $-0.0255^{\text {ns }}$ & $0.07887^{\mathrm{ns}}$ & $-0.0714^{\mathrm{ns}}$ & $0.3455^{* *}$ & $-0.1111^{\mathrm{ns}}$ & $0.3455^{*}$ & $0.2619^{\mathrm{ns}}$ & $0.0753^{\mathrm{ns}}$ & $-0.1321^{\mathrm{ns}}$ \\
\hline$F d h-2$ & $-0.2245^{\mathrm{ns}}$ & $0.2192^{*}$ & $-0.0097^{\mathrm{n}}$ & $0.1233^{\mathrm{ns}}$ & - & $0.1361^{\mathrm{ns}}$ & $-0.1442^{\text {ns }}$ & $0.2063^{\mathrm{ns}}$ & $0.4180^{*}$ & $-0.0753^{\mathrm{ns}}$ \\
\hline$I d h-1$ & - & $-0.2000^{\mathrm{n}}$ & $0.2593^{\mathrm{ns}}$ & $-0.4286^{*}$ & $0.1111^{\mathrm{ns}}$ & $0.3455^{*}$ & - & $-0.0169^{\mathrm{ns}}$ & $-0.0714^{\mathrm{ns}}$ & $-0.6667^{*}$ \\
\hline$I d h-2$ & - & $-0.1765^{\mathrm{n}}$ & $-0.0753^{\text {ns }}$ & $-0.0169^{n}$ & $-0.0909^{\mathrm{ns}}$ & $-0.2000^{\mathrm{ns}}$ & - & $-0.0345^{\mathrm{ns}}$ & $-0.0526^{\mathrm{ns}}$ & $-0.0909^{\text {ns }}$ \\
\hline$M d h-1$ & $0.5065^{*}$ & $-0.2500^{\mathrm{ns}}$ & $-0.0526^{\mathrm{n}}$ & $-0.1111^{\mathrm{ns}}$ & $-0.1321^{\mathrm{ns}}$ & $-0.1765^{\mathrm{ns}}$ & $-0.0526^{\mathrm{ns}}$ & $-0.1321^{\mathrm{ns}}$ & $-0.0909^{\text {ns }}$ & $-0.1556^{\mathrm{ns}}$ \\
\hline$M d h-3$ & $0.3778^{*}$ & $-0.1538^{\text {ns }}$ & $-0.2766^{\mathrm{ns}}$ & - & $-0.2500^{\mathrm{ns}}$ & $-0.1321^{\mathrm{ns}}$ & $-0.3953^{*}$ & $-0.2245^{\mathrm{ns}}$ & $-0.0169^{\mathrm{ns}}$ & - \\
\hline$\underline{\text { Pgd-1 }}$ & $0.4643^{*}$ & $-0.2500^{\mathrm{n}}$ & $-0.2500^{\mathrm{n}}$ & $0.4643^{*}$ & $-0.0526^{\mathrm{n}}$ & $-0.0714^{\mathrm{n}}$ & $0.3939^{*}$ & - & $0.6296^{* *}$ & $0.6491^{* *}$ \\
\hline
\end{tabular}

ns: $p \geqslant 0.05 *: p<0.05 * *: p<0.01$

表 6 云杉 10 个群体在不同位点上的基因多样性的构成和遗传分化

Table 6 Constitution and differentiation of gene diversity of 10 populations in Picea asperata at all loci

\begin{tabular}{|c|c|c|c|c|c|}
\hline $\begin{array}{l}\text { 位点 } \\
\text { Locus }\end{array}$ & $\begin{array}{c}\text { 总遗传多样性 } H_{\mathrm{T}} \\
\text { The total gene } \\
\text { diversity }\end{array}$ & $\begin{array}{c}\text { 群体内遗传多样性 } H_{\mathrm{S}} \\
\text { The gene diversity } \\
\text { within population }\end{array}$ & $\begin{array}{c}\text { 群体间遗传多样性 } D_{\mathrm{ST}} \\
\text { The gene diversity } \\
\text { among populations }\end{array}$ & $\begin{array}{l}\text { 遗传分化系数 } G_{\mathrm{ST}} \\
\text { The coefficient of gene } \\
\text { differentiation among } \\
\text { population with species }\end{array}$ & $\begin{array}{c}\text { 基因流 } N_{\mathrm{m}} \\
\text { Gene flow }\end{array}$ \\
\hline Aat-2 & 0.2182 & 0.2036 & 0.0146 & 0.0669 & 3.5034 \\
\hline$F d h-2$ & 0.4663 & 0.3990 & 0.0673 & 0.1443 & 1.4833 \\
\hline Idh-l & 0.3279 & 0.1848 & 0.1431 & 0.4364 & 0.3227 \\
\hline$I d h-2$ & 0.2192 & 0.1033 & 0.1159 & 0.5287 & 0.2228 \\
\hline$M d h-1$ & 0.3506 & 0.2136 & 0.1370 & 0.3908 & 0.3896 \\
\hline$M d h-3$ & 0.3665 & 0.2584 & 0.1081 & 0.2950 & 0.5982 \\
\hline Pgd-1 & 0.3896 & 0.2483 & 0.1413 & 0.3627 & 0.4394 \\
\hline 平均值 Mean & 0.3340 & 0.2301 & 0.1039 & 0.3178 & 0.5539 \\
\hline
\end{tabular}

Weinberg 平衡, 平均异交率 $(\mathrm{tm})$ 高, 为 0.957 (变幅为 0.536 1.000), 表明群体内不存在显著的近交效应 (表 3)。

\section{2 群体间遗传分化与基因流}

为了确定云杉天然群体同工酶位点上的变异总 量, 及在群体间和群体内的分布状况, 对群体变异作 基因多样度的等级分析, Nei 基因多样性指数 $(H)$ 是 衡量群体遗传分化最常用指标, 表示在总的遗传变 异中群体间变异所占比例, 同时也反映群体中等位 基因丰富度和均匀度。根据等位基因频率估算出总 的和群体内的基因多样度 $\left(H_{T} 、 H_{S}\right)$ 以及基因分化系 数 $\left(G_{S T}\right)$ (表 6 )。从表 6 可以看出, 云杉天然群体间 遗传分化系数 $\left(G_{S T}\right)$ 为 0.3178 , 也就是说云杉群体 间变异占总变异的 $31.78 \%$, 群体间分化大; 根据云 杉群体间的遗传分化系数计算的基因流低 $\left(N_{\mathrm{m}}=\right.$ $0.5539)$, 说明遗传漂变已开始成为刻化云杉天然 群体间遗传分化的原因之一。

当群体内个体随机交配不能实现时, 群体势必 发生一定程度的遗传分化, 群体的基因分化程度常 用 Wright 的 $F$ 统计量来描述, 可检测群体及其亚群 体中基因型实际比例与 Hardy-Weinberg 理论期望比
例的偏离程度, 云杉 10 个群体 7 个位点的 $F$ 统计量 分解值和 $N_{\mathrm{m}}$ 值见表 7。 $F_{\mathrm{st}}$ 的平均值为 0.311 (变幅 从位点 Aat-2 的 0.067 到位点 $I d h-2$ 的 0.529), 表明 云杉群体水平基因型偏离了 Hardy-Weinberg 平衡, 群体存在轻微纯合子过量现象。 $F_{\text {it }}$ 表示总群体中 基因型的实际频率和理论预期频率的离差, $F_{\mathrm{it}}$ 平均 值为 0.314 (从位点 $A a t-2$ 的 0.114 到位点 $I d h-2$ 的 0.468 ), 且所有位点的 $F_{\mathrm{it}}$ 均为正值, 表明所有位点 杂合体比率小于期望值, 即群体中纯合体稍微过量 的位点占全部位点的 $100 \%$ 。从表 6 可以看出, 云杉 群体 7 个多态位点在群体间的分化系数明显差异, $I d h-2$ 位点的分化程度最大 (0.529), Aat-2 位点的分 化程度最低 (0.067)。 $F_{\mathrm{st}}$ 可以度量群体间的分化程 度, 与常用的基因分化系数 $G_{\mathrm{ST}}$ 有相同的意义, 从表 7 分析结果看, $F_{\mathrm{st}}$ 为 0.311 , 基因与基因多样度方算 出的 $G_{\mathrm{ST}}(0.3178)$ 结果大致吻合。再从表 3 的 Shannon 信息指数 $(I)$ 分析显示, 10 个群体的平均表 型多样度值的变动为 $0.1152 \sim 0.2056$ 之间, 以川 盘最多, 黑水最低。种级水平的 $I$ 为 0.224 , 群体 内平均 $I$ 为 0.1588 , 群体间和群体内遗传多样性分 别占总遗传多样性的 $29.23 \%$ 和 $70.77 \%$, 就云杉群 
体分化而言, Nei 基因多样性指数和 Shannon 信息指 数的统计分析结果都显示云杉遗传多样性主要存在 于群体内, 群体间分化占 $31.78 \%$ 和 $29.23 \%$ 。仅 Nei 基因多样性指数的估算值稍高于 Shannon 信息 指数估算值。从表 7 可知, 云杉平均遗传分化度 $F_{\mathrm{st}}$ 为 0.311 ,即总遗传变异的 $31.10 \%$ 来源于群体间的 遗传变异, $68.90 \%$ 属于群体内的遗传变异。除位点 $A a t-2$ 外, 其余位点的 $F_{\text {st }}$ 值都显著偏离 0 值。

2.3 主要遗传参数的地理生态梯度变异
选取 7 个多态位点的大量基因(总群体中出现 频率最大者), 分别与经度、纬度、海拔、年降水、年均 温和综合生态值进行相关分析。结果显示, 只有 $F d h-2-B$ 基因与综合生态梯度值呈显著的负相关 $(r$ $\left.=-0.6611^{*}\right)$; 主要遗传参数 - 每个位点等位基因 的数目 $(A)$ 、多态位点的百分率 $(P)$ 和观测的杂合度 $\left(H_{\mathrm{e}}\right)$ 与上述地理生态因子的相关分析结果表明, $H_{\mathrm{e}}$ 与经度呈显著负相关 $\left(r=-0.683^{*}\right)$ 。

表 7 云杉 10 个群体 7 个多态位点上的 $\boldsymbol{F}$ 计量

Table 7 Summary of $F$-statistics at 7 loci of ten populations of Picea asperata

\begin{tabular}{|c|c|c|c|c|c|}
\hline $\begin{array}{c}\text { 基因位点 } \\
\text { Locus }\end{array}$ & $\begin{array}{c}\text { 固定指数 } F_{\text {is }} \\
\text { Inbreeding coefficieat }\end{array}$ & $\begin{array}{c}\text { 配子贡献度 } \\
F_{\text {it }} \\
\end{array}$ & $\begin{array}{c}\text { 群体间分化度 } F_{\text {st }} \\
\text { Differeatiation coefficient }\end{array}$ & $\begin{array}{l}\text { 基因流 } N_{\mathrm{m}} \\
\text { Gene flow }\end{array}$ & $\begin{array}{l}\text { Heterogeneity of allele frequency } \\
\qquad \chi^{2}(p)\end{array}$ \\
\hline Aat -2 & 0.051 & 0.114 & 0.067 & 3.5034 & ns \\
\hline Fdh-2 & 0.064 & 0.199 & 0.144 & 1.4833 & * \\
\hline$I d h-1$ & -0.263 & 0.288 & 0.437 & 0.3227 & $* * *$ \\
\hline$I d h-2$ & -0.130 & 0.468 & 0.529 & 0.2228 & $* * *$ \\
\hline$M d h-1$ & 0.001 & 0.391 & 0.391 & 0.3896 & $* * *$ \\
\hline$M d h-3$ & -0.1418 & 0.191 & 0.295 & 0.5982 & $* * *$ \\
\hline$P g d-1$ & 0.288 & 0.546 & 0.363 & 0.4394 & $* * *$ \\
\hline 平均值 Mean & 0.005 & 0.314 & 0.311 & 0.5539 & $* * *$ \\
\hline
\end{tabular}

$F_{\mathrm{it}}$ : Inbreeding coficent at the total sample level ns: $p \geqslant 0.05 \quad *: p<0.05 \quad * *: p<0.01 \quad * * *: p<0.0$

\section{3 讨 论}

\section{1 云杉天然群体的遗传多样性}

等位酶标记实验结果表明: 云杉种级水平遗传 多样性为: $P_{\mathrm{s}}=41.18 \%, A_{\mathrm{s}}=1.588, A_{\mathrm{es}}=1.2163$, $H_{\mathrm{ep}}=0.1378$ 。低于 Hamrick 和 Golt（1989）曾总结 55 种裸子植物同工酶遗传多样性水平 $\left(P_{\mathrm{s}}=\right.$ $\left.70.90 \%, A_{\mathrm{s}}=2.26, H_{\mathrm{ep}}=0.173\right)$, 低于葛颂 (1989)总 结 25 种针叶树同工酶遗传多样性水平 $\left(P_{\mathrm{s}}=\right.$ $\left.61.50 \%, A_{\mathrm{s}}=2.26, H_{\mathrm{ep}}=0.206\right)$, 低于张含国等 (2003) 总结国内外云杉同工酶遗传多样性水平 $(P \mathrm{~s}$ $\left.=47.90 \%, A_{\mathrm{s}}=1.78, H_{\mathrm{ep}}=0.242\right)$, 低于李斌等 (2003) 总结松属植物等位酶遗传多样性参数 $\left(P_{\mathrm{s}}=\right.$ $\left.68.80 \%, A_{\mathrm{s}}=1.982, H_{\mathrm{ep}}=0.175\right)$, 云杉天然群体内 的遗传多样性水平在云杉属植物中属于中等偏下水 平, 10 个群体多态位点的百分率 $(P)$ 为 $37.07 \%$ (变 幅为 $29.41 \% \sim 41.18 \%$ ), 平均每个位点等位基因数 目为 1.45 个 (变幅为 $1.353 \sim 1.588$ ), 高于已研究过 云杉属其它树种, 但低于欧洲云杉水平, 1980 2002 年国外报道云杉属植物的期望杂合度 $\left(H_{\mathrm{e}}\right)$ 的平均 值为 0.155 (罗建勋和顾万春, 2004a，2004b), 国内研 究青海云杉和红皮云杉的期望杂合度均值为 0.205 ,
云杉的期望杂合度较低, 平均为 $0.097,10$ 个群体中 期望杂合度最高为川盘群体 $\left(H_{\mathrm{e}}=0.1306\right)$, 其次为 卓尼群体 $\left(H_{\mathrm{e}}=0.1149\right)$, 再其次为铁布 $\left(H_{\mathrm{e}}=\right.$ $0.1082)$ 和大录群体 $\left(H_{\mathrm{e}}=0.1067\right)$, 上述 5 个群体 $H_{\mathrm{e}}$ 均在平均数以上。一般而言, 分布范围广、长寿 命植物和异交率高的种趋向于拥有更高的遗传多样 性( Hamrick \& Godt, 1989; Hamrick et al., 1992; Gitzendanner \& Soltis, 2000)。该研究结果表明, 云杉 天然群体的异交率高, 也属长命植物。造成目前云 杉遗传多样性水平偏低的主要原因很可能与该树种 的起源和分化、群体的人工选择强度和群体处的生 态环境有关。古化石和花粉研究表明, 该树种历史 上曾经历过“瓶颈效应”, 最后一次冰川后, 云杉和其 它北温带的针叶林被保留在青藏高原狭小的避难所 内, 在进化过程中又经历长期的地理隔离 (吴中伦, 1959; Fang, 1996), 云杉的有限分布 (跨度 $5^{\circ} \mathrm{E} 、 5^{\circ} 50^{\prime}$ $\mathrm{N}$ )(分布区 $102^{\circ} \sim 107^{\circ} \mathrm{E}, 30^{\circ} \sim 35^{\circ} 50^{\prime} \mathrm{N}$ ) 为我国近代 主要用材树种种源(群体)研究中地理分布区最小的 树种, 近代由于该树种是西部高原云杉属树种中垂 直分布最低, 生长最快的云杉属树种, 天然资源曾遭 受过强度的破坏, 这些可能是该树种遗传多样性偏 低的主要原因,再有云杉处于中国云杉属树种起源 
和分化中心, 正处于分化早期阶段, 易受奠基者效应 的影响(杨玉坡, 1983)。

\section{2 云杉的遗传分化}

根据 Hamrick 等 (1992) 总结的多年生木本植物 的 $G_{\mathrm{ST}}$ 值, 特有植物种 $G_{\mathrm{ST}}=0.141 \pm 0.049$, Ellstand 和 Elam (1993)认为 $G_{\mathrm{ST}}>0.1$ 意味着群体间变异程 度高, 云杉的 $G_{\mathrm{ST}}=0.3178$, 均大于 0.1 , 表明云杉群 体间分化很大。杂合基因多样度比率 $F_{\mathrm{st}}$ 为 0.311 , 显示群体间遗传分化较高, 杂合度大小能反映等位 基因丰富程度, 云杉天然群体内遗传变异占观测到 总变异的 $31.1 \%$, 高于国内外已研究云杉植物群体 分化度的均值 (25.75\%)(张含国等, 2003), 是松科 树种群体间遗传分化平均水平的 4 5 倍左右 (Hamrick \& Godt, 1992), 云杉高水平的群体间变异, 可能 主要是群体间等位基因频率差异引起的, 特别是卓 尼群体 (ZN), 事实上, 如果 $\mathrm{ZN}$ 群体不参加统计分析 时, 群体间的 $F_{\mathrm{st}}$ 为 0.178 , 根据群体间遗传距离的 UPGMA 聚内图中, ZN 群体首先单独聚为一类, 该群 体遗传的特异性, 有可能是外来树种的渗透、其它云 杉杂交或花粉的污染造成的。可能与群体遭受的强 度破坏和“岛式”分布有关, 自然分布区垂直跨度大 (海拔 $1600 \sim 4300 \mathrm{~m}$ ), 地貌类型复杂 (分布区包括 高山狭谷区, 高原丘陵区和山原区 3 个典型地貌类 型), 跨不同水系 (岷江、大渡河和黄河)。影响群体 遗传结构的因素, 除繁殖系统、分布范围外, 基因流 也是一个重要因素。据 Slatkin(1985) 的观点, 群体 之间的基因流用群体每代迁移数 $\left(N_{\mathrm{m}}\right)$ 来度量, 若每 代迁入个数 $N_{\mathrm{m}}$ 大于 1 , 基因流就是以抵制遗传漂变 的作用, 也同时防止了群体分化的发生; 若 $N_{\mathrm{m}}$ 小于 1 , 漂变就成为刻划群体遗传结构的主导因素, 该研 究 10 个群体的基因流 $N_{\mathrm{m}}=0.5539$; 云杉自然分布 区北部的铁布群体检测出特有基因 ( Idh-2-C), Fdh$2-B$ 基因与综合生态梯度值呈显著的负相关 $(r=$ $\left.-0.6611^{*}\right)$; 观察杂合度 $\left(H_{\mathrm{e}}\right)$ 与经度呈显著负相关 $\left(r=-0.683^{*}\right)$ 。进一步说明云杉天然群体间地理 生态环境的差异是造成云杉基因分化/自然分布区 的西北部天然群体遗传多样性富集的主要原因之一 (罗建勋,2004)。

\section{3 遗传多样性保护和树种改良}

云杉种内遗传多样性在云杉属植物中处于中等 偏低水平, 群体间遗传分化处高水平, 总遗传变异大 约 30\% 存在群体间, 大约 70\% 存在群体内。由于云 杉群体间分化大, 必须采取有效的措施保护现有天 然群体, 特别是自然分布区边缘群体的保护尤为重
要。若进行迁地保护时要尽量选择代表性广泛的群 体, 特别是自然分布区东西南北的边缘群体, 由于群 体内遗传变异占总变异的 $70 \%$ 左右, 每个群体多取 样, 铁布、卓尼、川盘、大录和巴西 5 个群体所在区域 加以重点保护可以收到事半功倍的效果。种质资源 科学保护评价时最终目的是合理利用。群体改良 (种源和林分选择) 是该树种遗传改良的一部分, 种 源试验采种点确定必须尽可能涵盖边缘群体; 另一 方面, 云杉群体内变异占总变异的 $70 \%$ 左右, 在群 体改良基础上加强群体内优良家系和无性系的选 择。

\section{参 考 文 献}

Chen SY (陈少瑜), Wu LY (吴丽圆), Li JW (李江文), Xiang W(项伟), Zhou Y(周云) (2001). Study on genetic diversity of natural population of Taxus yunanensis. Scientia Silvae Sinicae (林业科学), 37 (5), 41 - 48. (in Chinese with English abstract)

Ellstrand NC, Elam DR(1993). Population genetic consequences of population size: implications for plant conservation. Annual Review of Ecology and Systematic, 24,217-242.

Fang JY (方精云) (1996). The distribution pattern of Chinese natural vegetation and its climatological and topographic interpretations. In: Fang JY (方精云) ed. Researches on Hotspots of Modern Ecology (现代生态学热点问题研究). China Science and Technology Press, Beijing, 369 - 380. (in Chinese)

$\mathrm{Ge}$ S(葛颂) (1988). Isozymes and studies on population genetic variation in forest trees. Journal of Nanjing Forestry University (南京林业大学学报), 12(1),68-77. (in Chinese with English abstract)

Ge S(葛颂) (1989) Quantitative analysis of tree population variation by allozyme and analysis method. Journal of Southwest Forestry College (西南林学院学报),9(1), 84 -91. (in Chinese with English abstract)

Gu WC(顾万春), Wang Q(王棋), You YT(游应天), Sun CL (孙翠玲) (1998). Introduction to Forestry Genetic Resources (森 林遗传资源学概论). China Science and Technology Press, Beijing, 1 - 296. (in Chinese)

Gu WC (顾万春) (2004). Statistics Genetics (统计遗传学). Science Press, Beijing, 1-422. (in Chinese)

Gitzendanner MA, Soltis PS (2000). Patterns of genetic variation in rare and widespread plant congeners. American Journal of Botany, $87,782-792$.

Hamrick JL, Godt MJ (1989) . Allozyme diversity in plant species. In: Brown ADH, Clegg MT, Kahler AL, Weir BS eds. Plant Population Genetic, Breeding, and Genetic Resources. Sinauer Associates, Sunderland, $43-46$.

Hamrick JL, Godt MJW. Sherman-Broyes SL (1992). Factors influencing levels of genetic diversity in woody plant species. New 
Forest, 6, 95 - 124 .

Kim ZS, Yi Cheng Ho, Seock woolee(1994). Genetc variation and sampling strategy for conversation in Pinus species . In: Kim ZinSuh, Hans HH eds. Conversation and Manipulation of Genetic Resources in Forestry. Kwang Moon Kag, Soul, 294-319.

Ledig FT, Bermejo-Velázquez B, Hodgskiss PD, Johnson DR, FloresLópez C, Jacob-Cervantes V (2000). The mating system and genetic diversity in Martínez spruce, an extremely rare endemic of México's Sierra Madre Oriental: an example of facultative selfing and survival in interglacial refugia. Canadian Journal of Forest Research, 30, 1156 - 1164 .

Li XQ (李晓清), Luo JX (罗建勋) (2001). A study on division of provenance of woodpulp stands of Picea asperata. Journal of Sichuan Agricultural University (Natural Science Edition) (四川 农业大学学报 (自然科学版)), 19, 34 - 36. (in Chinese with English abstract)

Li B (李斌), Gu WC (顾万春), Lin FR (林富荣), Lu BM (卢 宝明) (2003). Review on genetic diversity in Pinus. Hereditas (遗传), 25,740 - 748. (in Chinese with English abstract)

Luo JX (罗建勋), Zuo L (左林) (2001). A preliminary study on variation pattern of wood natural for Picea asperata plantation. Journal of Northwest Science-technology University of Agriculture and Forestry (Natural Science Edition) (西北农林科技大学学 报 (自然科学版) ), 29(3), 29 34. (in Chinese with English abstract)

Luo JX (罗建勋), Li XQ (李晓清), Sun P (孙鹏) (2003). Phenotypic variation in natural populations of Picea asperata. Journal of Northeast Forestry University (东北林业大学学报), 31(1),9-11. (in Chinese with English abstract)

Luo JX (罗建勋), Gu WC (顾万春) (2004a). Cone and seed variation of natural population in Picea asperata. Journal of Northwest Science-technology University of Agriculture and Forestry (Natural Science Edition) (西北农林科技大学学报 (自然科 学版) ), 32(8),60-66. (in Chinese with English abstract)

Luo JX (罗建勋), Gu WC (顾万春) (2004b) Progress in genetic diversity of Picea at phenotype and allozyme level. Forest Research (林业科学研究) , 17, 255 - 262. (in Chinese with English abstract)

Luo JX (罗建勋) (2004). Genetic Diversity of Natural Populations in Picea asperata (云杉天然群体遗传多样性研究). $\mathrm{PhD}$ dissertation, Institute of Forestry, Chinese Academy of Forestry. Beijing, 85-92. (in Chinese with English abstract)

Luo JX (罗建勋), Gu WC (顾万春) (2005). Study on phenotypic diversity of natural population in Picea asperata. Scientia Silvae Sinicae (林业科学), 41 (2), 66 - 73. (in Chinese with
English abstract)

Modrzynski J, Prus Glowacki W (1998). Isoenzymatic variation in some of the polish populations of Norway spruce (Picea abies) in the IUFRO-1972 province trial. Acta Societatis Botanicorium Poloniae, 67, 75-82.

Rajora OP, Mosseler A, Major JE(2000). Indicators of population viability in red spruce Picea rubens. II . Genetic diversity, population structure and mating behaviour. Canadian Journal of Botany, 78, 947 - 956.

Slatkin M (1985). Rare alleles as indicators of gene flow. Evolution, $39,52-65$.

Swofford DL, Selander RB (1989). BIOSIS-1, a computer program for the analysis of allelic variation in population genetics and biochemical systematics. Journal of Heredity, 72, $281-283$.

Sun XX(孙雪新), Zha TS (查天山), Tao Y (陶毅) (1990). Isozyme variation of natural population in Picea crassifolia Koml. Journal of Gansu Forestry Science and Technology (甘肃林业科 技), (2), 11 15. (in Chinese with English abstract)

Wang YH, Luo JX, Xue XM, Korpelainen H, Li CY (2005). Diversity of microsatellite markers in the populations of Picea asperata originating from the mountains of China. Plant Science, 168, $707-714$.

Wu ZL (吴中伦) (1959). The distribution of major tree species in alpine forest area of western Sichuan and some proposals for regeneration report and planning of tree species for plantation. Scientia Silvae Sinicae (林业科学), 5,465-478. (in Chinese with English abstract)

Yang YP (杨玉坡) (1983). The spruce in China. Journal of Sichuan Forestry Science and Technology (四川林业科技), 4 (3) ,28 - 32. (in Chinese with English abstract)

Yang RC, Yeh FC (1993). Multilocus structure in Pinus contorta. Theoretical and Applied Gentics, 87, 568-576.

Zhang HG (张含国), Yang DH (杨大海), Wang FJ (王风君), Zhou Y (周云) (2000). Selection of allozyme loci and enzyme systems of Picea koraiensis. Journal of Northeast Forestry University (东北林业大学学报), 28(2),9-12. (in Chinese with English abstract)

Zhang HG (张含国), Sun LF (孙立夫), Han JF (韩继风), Feng BL (丰宝林) (2003). Study on the genetic diversity of Picea koraiensis. Bulletin of Botanical Rsearch (植物研究) ,25, 224 229. (in Chinese with English abstract)

Zhou SL(周世良), Zhang F(张方), Wang ZR(王中仁) (1998). Some advices for starch gel eletrophoresis in allozyme analysis. Chinese Bulletin of Botany (植物学通报), 15(5),68-72. (in Chinese with English abstract) 